\title{
IN-VIVO CLINICAL EVALUATION OF REGENERATIVE ENDODONTICS IN IMMATURE NECROTIC PERMANENT TEETH WITH OPEN APEX
}

Prem Lata $^{1}$ Ajay Chhabra ${ }^{2}$ Varun Jindal ${ }^{3}$ Damanpreet $^{4}$ Arun Kumar Thakur ${ }^{5}$ ${ }^{1}$ PG Student, Department of Conservative Dentistry and Endodontics, Bhojia Dental College \& Hospital, Himachal Pradesh, India ${ }^{2}$ Professor \& Head, Department of Conservative Dentistry \& Endodontics, Bhojia Dental College \& Hospital, Himachal Pradesh, India ${ }^{3}$ Reader, Department of Conservative Dentistry \& Endodontics, Bhojia Dental College \& Hospital, Himachal Pradesh, India ${ }^{4}$ Reader, Department of Conservative Dentistry \& Endodontics, Bhojia Dental College \& Hospital, Himachal Pradesh, India ${ }^{5}$ Private Practictioner, Himachal Pradesh, India

\begin{abstract}
Introduction: This study was conducted to evaluate clinical and radiographic findings induced by revascularization with and without platelet-rich plasma (PRP). Methods: Twenty patients with nonvital, immature anterior teeth were randomly categorized into 2 groups. Subsequent to minimal instrumentation of the root canal, disinfection was achieved with ledermix paste and followed by revascularization with and without PRP in groups I and II, respectively. The cases were followed up clinically and radiographically at 6and 12-month intervals. Results: Clinically, all cases were asymptomatic with complete resolution of signs and symptoms (except four cases which were considered as dropout). Radiographically, there was no significant difference in periapical healing, apical closure, and dentinal wall thickening in group I in comparison with group II. However, root lengthening was comparable for both of the procedures. Conclusions: Revascularization is a conservative and an effective method for inducing maturogenesis in nonvital, immature teeth. Supplementations with PRP can potentially improve the desired biological outcome of this regenerative procedure.
\end{abstract}

Keywords: Apical closure Regenerative, Revascularization, Scaffold.

\section{INTRODUCTION}

Trauma or carious exposure in immature permanent teeth can lead to pulp necrosis, infection and arrested root development. The consequences of arrested development include roots with thin dentinal walls, open apices and an increased risk of root fracture. 'The conventional treatment protocol of root canal instrumentation, disinfection and sealing is technically more difficult to perform in these cases. Traditionally, immature teeth were treated by apexification consisting of using longterm calcium hydroxide dressings in an attempt to induce a calcific barrier at the apex before filling the root canals. ${ }^{2}$ The

Corresponding Author:

Prem Lata

E-mail:

drpremlatathakur@gmail.com

Received: $30^{\text {th }}$ November, 2014

Accepted: $30^{\text {th }}$ March, 2015

Online: $10^{\text {th }}$ May, 2015 calcium hydroxide apexification technique has been associated with variable treatment times from 3 to 21 months, multiple visits leading to inevitable high costs, poor patient compliance and risks of reinfection resulting from the difficulty in creating long-term seals with provisional restorations. $^{3}$

Regenerative endodontic procedure can be defined as biologically based procedure designed to replace damaged structures including dentin and root structure as well as the cells of the pulp dentin complex. ${ }^{4}$ Regenerative endodontics aims to restore vitality and function of the pulp dentin complex that has been lost due to trauma or infection.

Regenerative endodontics includes two types of procedures, namely root canal revascularization via blood clotting and stem-cell therapies such as post-natal stem-cell therapy, pulp implantation, scaffold implantation, injectable scaffold delivery, three- 
dimensional cell printing and gene delivery. ${ }^{4,6,7}$ Root canal revascularization via blood clotting aims to treat immature teeth with necrotic pulps by disinfecting the root canal system and then using over instrumentation to secure bleeding into the canal space to provide a scaffold for the ingrowth of tissues. ${ }^{7,89}$ In some of cases, bleeding in the root canal could not be produced. In these cases, authors proposed use of platelet-rich plasma (PRP) derived from the patient's whole blood as a scaffold. ${ }^{10}$

Although the current materials and methods demonstrated favorable clinical results, true and complete biological regeneration of the damaged or injured structures is not yet attainable. ${ }^{6}$ Studies regarding the use of Platelet Rich Plasma (PRP) in regenerative endodontic are limited in number and the literature includes mixed reports regarding tissue response to tests following revascularization treatment, with some authors reporting positive responses and others reporting negative responses to sensibility testing. ${ }^{8,11,12,13}$ This study was conducted to compare the clinical outcome of regenerative endodontics with Platelet Rich Plasma (PRP) and without PRP.

\section{METHODOLOGY}

This in-vivo study was conducted in the Department of Conservative and Endodontic Dentistry, Bhojia Dental College and Hospital, Baddi, from the year 2012-2014. Approval had been granted from the Ethical Committee for the study and consent was obtained from each patient prior to the treatment after explaining entire procedure

Twenty cases of immature non vital anterior teeth or single rooted teeth presenting with or without sign and symptoms of periapical pathology were included in the study. Intraoral periapical radiograph revealing immature apices either blunderbuss canals or wide canals with parallel walls or slight flaring in the apical end were recruited. Ages of the patient were in range of 16 to 25 years.

Detailed history and thorough clinical examination was done. A good quality preoperative radiograph was taken using extension cone paralleling technique. The patients were divided into two groups as group I in which teeth with periapical radiolucency were considered and group II with healthy periapical region or if radiolucency is present it should have been resolved before inducing bleeding into canal in second appointment.

\section{GROUP I: USING PLATELET RICH PLASMA}

\section{First Appointment}

After application of rubber dam, an access cavity was prepared on the tooth. After entry into the root canal necrotic pulp was removed with aid of 40 no $\mathrm{H}$-file. Working length was determined by placing 40 no. $\mathrm{K}$-file in the canal and taking a peri-apical radiograph. The canal was irrigated with approximately $10 \mathrm{ml}$ of $5.25 \% \mathrm{NaOCl}$ and dried with paper points. Then pulp chamber was sealed with bonding agent (Te-Econom Bond) and light cured. After this ledermix paste (Blackwell, UK) was placed throughout canal space with the help of lentulospirals and the access cavity was sealed with cavit and patient was recalled after 22 days.

\section{Second Appointment}

Patient was recalled after 22 days. If the tooth was symptomatic to both percussion and palpation then tooth was irrigated with sodium hypochlorite and ledermix paste was again placed for 22 days until the tooth became asymptomatic. If tooth was aymptomatic, then $5 \mathrm{ml}$ of whole blood was drawn from the patient's right arm for platelet rich plasma preparation. After rubber dam isolation, temporary restoration was removed and ledermix paste was washed out by using $0.9 \%$ sterile saline irrigation. The canal was dried with paper points. After making PRP in centrifugal machine, it was placed in the canal space with the help of endodontic plugger and allowed to clot for 5 minutes. Then 2-3 mm of white MTA was placed over the PRP clot and a moist cotton pellet was placed over MTA followed by provisional restoration with cavit. Patient was recalled after 3 days. Then under rubber dam isolation the provisional restoration and cotton pellet was removed and sealed with glass ionomer cement (GC) and composite restoration (Ivoclar-Vivadent). The patient was rescheduled for recall examination and advised to call if he/she had pain or swelling.

\section{GROUP II: BY INDUCING PERIAPICAL BLEEDING}

First Appointment was performed in similar way to group I. 


\section{Second Appointment}

The patient was recalled after 22 days. If the tooth was symptomatic to both percussion and palpation then tooth was irrigated with sodium hypochlorite and ledermix paste was again placed for 22 days until the tooth became asymptomatic. In one case, patient was symptomatic after 3 intra canal dressings of ledermix, so tooth was considered for apexification.

If patient was asymptomatic, local anesthesia ( $2 \%$ lidocaine) without adrenaline was given. Under rubber dam isolation access was reopened and canal was flushed with $10 \mathrm{ml}$ of $5.25 \% \mathrm{NaOCl}$. Canal was dried with paper points. $\mathrm{K}$ file was inserted in the canal beyond the apex until vital tissue was felt (3-4mm). At that depth, instrument was used to irritate the tissue gently to create some bleeding into canal. Bleeding was stopped at a level of 2- $3 \mathrm{~mm}$ below the level of the CEJ and left for 15 minutes so that blood clot is formed at that level. After 15 minutes, Mineral trioxide aggregate (2-3mm) was carefully placed over the blood clot followed by wet cotton pellet and cavit.

After 3 days patient was recalled and under rubber dam isolation, cavit and moist cotton pellet was removed and access was sealed with Glass ionomer cement (GIC) and composite restoration (IvoclarVivadent)

\section{EVALUATION}

At 1,6 and 12- months recall, patient was examined clinically and radiographically. In clinical examination percussion and palpation tests were done. For vitality testing cold test and electric pulp test was conducted. In radiographic examination, standardized radiographic assessment, which includes: Periapical healing, An increase in root length, An increase in root thickness, A decrease in apical diameter (Figure 1).
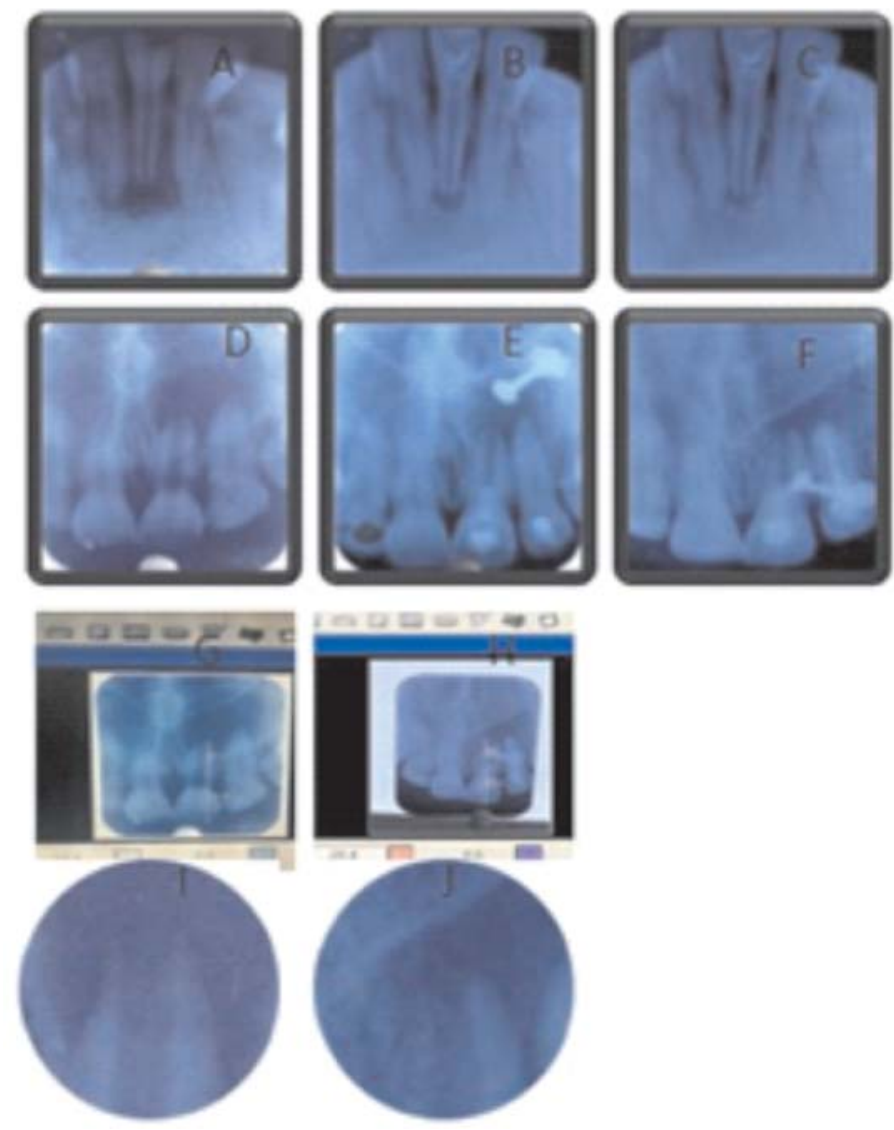

Figure 1: Group1 A: Diagnostic radiograph, Mandibular right central incisor. B: After PRP placement

C: 12 months follow up, Group II D: Diagnostic radiograph, maxillary left central incisor E: After inducing bleeding through apex,

F: 12 months follow up, G \&H: Root lengthening before and after, I\&J: Apical 3RD before and after 


\section{RESULTS}

A total of 20 immature permanent teeth fulfilling the previously stated criteria were collected from 17 patients (14 males and 3 females) were included in the study. Two males and one female had two incisors treated in both the groups. For the pulpal diagnosis all teeth had pulpal necrosis. Two cases each from both the groups were excluded and rest of the cases was followed up clinically and radiographically at 1, 6 and 12 months, with complete resolution of pain and swelling.

The clinical findings were assessed according to the presence of pulp sensitivity, spontaneous pain, and tenderness, pain on palpation, sinus tract, swelling, and crown discoloration (all the cases were asymptomatic). Pulp sensitivity was assessed by the cold thermal test by using ICE stick and by electric pulp test (Pulp Tester; Analytic Technology, Redmond, WA). The radiographic examination was evaluated for the following criteria: periapical lesion, root resorption, apical closure, root length, and root thickness. With Electric pulp tester 2 cases responded as sensitive while rest of the cases showed negative results. Root length was measured with KODEK IMAGING SOFTWARE and Increase in the root wall thickness and decrease in the apical diameter was seen by comparing radiographs for changes followed by statistical analysis of the results.
The statistical software SPSS PC + (Statistical Package for Social Sciences, Version 23) was used for statistical analysis.

- Electric pulp test: Percentage of positive test was $20 \%$ within the groups and Fisher's exact showed no-significant difference between both the groups.

- Cold test: Percentage of positive test was $20 \%$ within the groups and Fisher's exact showed nosignificant difference between both the groups.

- Periapical healing: Percentage of positive parameter was $70 \%$ in group I and $80 \%$ in group II and Fisher's exact showed no-significant difference between both the groups.

- Apical closure: Percentage of positive parameter was $60 \%$ in group I and $40 \%$ in group II. Results were non-significant within groups [ $p=0.587]$

- Root wall thickness: Percentage of positive parameter was $50 \%$ in group I and $20 \%$ in group II. Results were non-significant within groups [p=0.319]

- Root lengthening of both the groups were comparable. Mean in group 1 was $.837 \pm .324$ and mean in group II was $.500 \pm .250$. T- test of significance showed that results were significant $\left(\mathrm{p}=.036^{*}\right)($ Table $1 \& 2)$

Table 1: Summary of Patients

\begin{tabular}{|c|c|c|c|c|c|c|c|c|c|c|c|}
\hline \multicolumn{12}{|c|}{ Group I (PRP) } \\
\hline \multirow{2}{*}{$\begin{array}{l}\text { Sr. } \\
\text { No }\end{array}$} & \multirow{2}{*}{$\begin{array}{l}\text { Tooth } \\
\text { no }\end{array}$} & \multirow[t]{2}{*}{ Age/sex } & \multirow[t]{2}{*}{ Follow-up } & \multicolumn{4}{|c|}{ Clinical findings } & \multicolumn{4}{|c|}{ Radiographic findings } \\
\hline & & & & $\begin{array}{c}\text { Asympato } \\
\text {-matic }\end{array}$ & Ept & $\begin{array}{c}\text { Cold } \\
\text { test }\end{array}$ & $\begin{array}{l}\text { Percussion, } \\
\text { palpation }\end{array}$ & $\begin{array}{l}\text { Periapical } \\
\text {-healing }\end{array}$ & $\begin{array}{l}\text { Apical } \\
\text { closure }\end{array}$ & $\begin{array}{c}\text { Root } \\
\text { lengthening }\end{array}$ & $\begin{array}{l}\text { Root wall } \\
\text { thickness }\end{array}$ \\
\hline 1 & 41 & $26 / \mathrm{m}$ & $\begin{array}{l}1 \text { yr } 2 \\
\text { months }\end{array}$ & + & + & + & - & Present & Present & $1 \mathrm{~mm}$ & Present \\
\hline 2 & 11 & $16 / \mathrm{f}$ & 10 months & + & - & - & - & Present & Present & $0.7 \mathrm{~mm}$ & Absent \\
\hline 3 & 41 & $26 / \mathrm{m}$ & $1 \mathrm{yr}$ & + & - & - & - & Present & Present & $1.4 \mathrm{~mm}$ & Present \\
\hline 4 & 21 & $17 / \mathrm{m}$ & 11 months & + & - & - & - & Present & Present & $0.9 \mathrm{~mm}$ & Present \\
\hline 5 & 11 & $20 / \mathrm{m}$ & $1 \mathrm{yr}$ & + & - & - & - & Present & Present & $1 \mathrm{~mm}$ & Absent \\
\hline 6 & 21 & $21 / \mathrm{m}$ & $1 \mathrm{yr}$ & + & - & - & - & Absent & Absent & $0.8 \mathrm{~mm}$ & Present \\
\hline 7 & 11 & $21 / \mathrm{m}$ & $1 \mathrm{yr}$ & + & - & - & - & Present & Present & $0.3 \mathrm{~mm}$ & Present \\
\hline 8 & 21 & $22 / \mathrm{m}$ & Dropout & - & - & - & - & - & - & - & - \\
\hline 9 & 11 & $24 / \mathrm{m}$ & 8 months & + & - & - & - & Present & Absent & 0.6 & Absent \\
\hline 10 & 21 & $22 / \mathrm{f}$ & Dropout & - & - & - & - & - & - & - & - \\
\hline
\end{tabular}


Table 2: Summary of Patients

\begin{tabular}{|c|c|c|c|c|c|c|c|c|c|c|c|}
\hline \multicolumn{12}{|c|}{ Group II (bleeding induced through apex) } \\
\hline \multirow{2}{*}{$\begin{array}{l}\text { Sr. } \\
\text { No. }\end{array}$} & \multirow{2}{*}{$\begin{array}{l}\text { Tooth } \\
\text { no }\end{array}$} & \multirow[t]{2}{*}{ Age/sex } & \multirow{2}{*}{$\begin{array}{l}\text { Follow- } \\
\text { up }\end{array}$} & \multicolumn{4}{|c|}{ Clinical findings } & \multicolumn{4}{|c|}{ Radiographic findings } \\
\hline & & & & $\begin{array}{c}\text { Asympato- } \\
\text { matic }\end{array}$ & Ept & $\begin{array}{l}\text { Cold } \\
\text { test }\end{array}$ & $\begin{array}{c}\text { Percussion, } \\
\text { palpation }\end{array}$ & $\begin{array}{l}\text { Periapical- } \\
\text { healing }\end{array}$ & $\begin{array}{l}\text { Apical } \\
\text { closure }\end{array}$ & $\begin{array}{c}\text { Root } \\
\text { lengthening }\end{array}$ & $\begin{array}{c}\text { Root } \\
\text { wall } \\
\text { thickness }\end{array}$ \\
\hline 1 & 21 & $22 / \mathrm{f}$ & $1 \mathrm{yr}$ & + & + & + & - & Present & Present & $1 \mathrm{~mm}$ & Present \\
\hline 2 & 12 & $16 / \mathrm{m}$ & $1 \mathrm{yr}$ & + & - & - & - & Present & Present & $0.7 \mathrm{~mm}$ & Absent \\
\hline 3 & 11 & $22 / \mathrm{m}$ & $1 \mathrm{yr}$ & Dropout & - & - & - & - & - & - & - \\
\hline 4 & 11 & $21 / \mathrm{m}$ & $1 \mathrm{yr}$ & + & - & - & - & Present & Absent & $0.3 \mathrm{~mm}$ & Absent \\
\hline 5 & 21 & $20 / \mathrm{m}$ & $1 \mathrm{yr}$ & + & - & - & - & Present & Present & $0.3 \mathrm{~mm}$ & Absent \\
\hline 6 & 21 & $16 / \mathrm{m}$ & Excluded & - & - & - & - & - & - & - & - \\
\hline 7 & 21 & $16 / \mathrm{f}$ & 10months & + & - & - & - & Present & Present & $0.4 \mathrm{~mm}$ & Absent \\
\hline 8 & 22 & $22 / \mathrm{m}$ & $1 \mathrm{yr}$ & + & - & - & - & Present & Absent & $0.6 \mathrm{~mm}$ & Absent \\
\hline 9 & 21 & $26 / \mathrm{m}$ & 8 months & + & - & - & - & Present & Absent & $0.4 \mathrm{~mm}$ & Absent \\
\hline 10 & 33 & $17 / \mathrm{m}$ & 10 months & + & - & - & - & Present & Absent & $0.3 \mathrm{~mm}$ & Present \\
\hline
\end{tabular}

\section{DISCUSSION}

Recently, regenerative endodontics has gained much attention as a biologically based alternative. Regenerative approaches gained the advantage over apexification because they can allow for further root maturation in length and thickness by regenerated vital tissue. $^{14}$

Revascularization is the procedure to reestablish the vitality in a non-vital tooth to allow repair and regeneration of tissues. The rationale of revascularization is that if a sterile tissue matrix is provided in which new cells can grow, pulp vitality can be reestablished. Revascularization protocols are derived from the observations of reimplanted and autotransplanted teeth in experimental animals in which necrotic pulp, but free of infection, provided a matrix into which the cells from the periapical tissues could grow and reestablish pulp vascularity, slowly replacing the necrotic tissue. ${ }^{15}$

Various studies ${ }^{4,9,11,15,28}$ have been done earlier on revascularization by inducing bleeding through apex, but very few studies have been done on revascularization with the use of platelet-rich plasma. So this study will add another case series to the existing literature.

Root canal walls of immature teeth are very thin, so there was concern of further weakening of the root canal walls if traditional instrumentation was performed. Minimal-to-no mechanical debridement technique was supported by most of the regenerative endodontic procedures. ${ }^{11,15,16,17,18,19}$ Thus after access preparation, minimal-to-no mechanical instrumentation technique was performed in this study.

In this study, sodium hypochlorite $5.25 \%$ was used as an effective irrigant. Disinfection of the root canal is an important criteria for success of regenerative procedures, so for complete disinfection bacterial biofilm on the canal wall needs to be mechanically disrupted in order to allow antimicrobial agents to permeate the biofilm and kill bacterial cells. ${ }^{20}$ Various authors have used different medicaments (triple antibiotic paste, calcium hydroxide and ledermix paste) for disinfection of root canal. ${ }^{81,9,10,21}$

In this study, ledermix paste (triamicinolone + demeclocycline) (Blackwell, Germany) was used as an intra canal medicament and it's use has been supported by various other studies..$^{21,22,23,24,25}$ Ledermix paste (potent anti-inflammatory corticoid triamcinolone acetonide in combination with the broad-spectrum antibiotic demeclocycline) has advantage of inhibition of resorption in cases of traumatized teeth over various combinations of antibiotics. . $^{21,22,23,24,25}$

The PRP clot is believed to provide an excellent matrix for the placement of mineral trioxide aggregate and subsequent permanent restorations to prevent coronal leakage. ${ }^{19}$ PRP has increased concentrations of growth factors that can attract stem cells present in the apical tissues (ie, vital pulp cells, periodontal ligament, apical dental papilla, and bone marrow) and even from periapical lesions. ${ }^{19,28}$ Platelet concentration in PRP exceeds 1 million $/ \mathrm{mL}$, which is 5 times more than that of the normal platelet count. It is a concentrated suspension of different growth factors 
like platelet-derived vascular endothelial growth factor, epidermal growth factor, and epithelial cell growth factor. $^{24}$

The advantages of using PRP include its relative ease of application and shorter time to induce vital tissues within the root canal system. The disadvantages of this procedure include drawing blood in young patients, need of special equipment and medications to prepare PRP, and increased cost of treatment. ${ }^{28}$

MTA (Mineral trioxide) was placed over the blood clot to isolate the root canal from the external surface of the tooth and create a hard tissue barrier at its contact point with the blood clot which was supported by other studies also. ${ }^{1,910,12,18,26}$ Over MTA moist cotton pellet ( to allow its setting for $72 \mathrm{hrs}$ ) and cavit was given. After 72 hrs, cavit was removed and set MTA was double-sealed with permanent filling materials (glass ionomer cement followed by composite resin restoration). ${ }^{28}$

In group II, procedures were performed according to the principles (blood clot scaffold, and bacteria tight coronal seal) of Banchs and Trope. ${ }^{17,9}$ Local anesthetic lignocaine without vasoconstrictor was administered to patients. Vasoconstrictor was avoided because it can inhibit flow of blood after irritation into the required site. Blood clot in the disinfected canal space might have acted as matrix for the growth of new tissue as has been recommended in earlier case reports by Murray and Banch \&Trope or new tissue may have grown from the apical papilla which contains stem cells. ${ }^{4,9}$

Statistical analysis of results showed that there was significant difference in increase in root length parameter while rest of the parameters showed no significant differences. The treatment outcomes of root length were better in the revascularization + PRP (group I) when compared with the group treated with revascularization (group II) alone (Table 1 and 2).

The literature also includes mixed reports regarding tissue response to tests following revascularization treatment, with some authors reporting positive responses( Iwaya et al. 2001, Ding et al. 2009, Petrino et al. 2010, Torabinejad \& Turman
2011) and others reporting negative responses( Cehreli et al. 2011) to sensibility testing. ${ }^{1921,23,38}$ The negative responses to sensibility tests in these cases may be attributed to the thick layers (3-4 mm) of MTA, and reinforced glass-ionomer cement $(2 \mathrm{~mm})$ followed by composite resin used as the permanent restoration. ${ }^{6}$

Although a positive response to a pulp test is not conclusive for the regeneration of pulp tissue in the canal space, it is one of the requirements for showing regeneration. It is important to note that the lack of a pulp response in teeth that underwent REPs does not necessarily indicate a lack of vitality. ${ }^{32,8,9,10,12,28,33}$

The continued root growth may be attributed to many mechanisms. One possible mechanism postulates that few vital pulp cells remain at the apical canal end. ${ }^{15}$ Another hypothesized mechanism depends on periodontal ligament stem cells. ${ }^{9}$ The third possible mechanism relies on stem cells of apical papilla (SCAPs) in which instrumentation beyond the apical limit of the canal leads to the transplantation of SCAPs into the canal lumen. The fourth possible mechanism involves the blood clot itself. The formed blood clot is considered a reservoir of growth factors including platelet-derived growth factor, vascular endothelial growth factor, and tissue growth factors. ${ }^{11}$

Chen et al, followed 20 teeth that had undergone REPs and described 5 types of responses: ${ }^{32,16}$

1 Increased thickening of the canal walls and continued root maturation

2 No significant continuation of root development with the root apex becoming blunt and closed

3 Continued root development with the apical foramen remaining open

4 Severe calcification (obliteration) of the canal space

5 A hard-tissue barrier formed in the canal between the coronal MTA plug and the root apex

In our study we have seen type 2 healing in most of the cases as suggested by Chen et al. ${ }^{16}$

\section{CONCLUSION}

Revascularization of the immature necrotic permanent teeth is a clinical possibility; a treated tooth might even respond normally to electric pulp test after 
about a year. This treatment modality should be preferable to the traditional apexification treatment. The traditional techniques for treatment of teeth with immature root development and necrotic pulp including induction of hard tissue barrier via calcium hydroxide apexification or an artificial hard tissue barrier of MTA without further development of the root walls and apex, may one day be replaced if revascularization is shown to be predictable in controlled research models. Shifting apexification to apexogenesis even for teeth that show a negative response to pulp vitality test and with periradicular periodontitis or abscess is a clinically beneficial approach for the patients.

The present clinical study offerd several advantages over other established treatment protocols for management of immature, infected non-vital teeth. However, longer the case series with longer follow-up period is required to establish it as the standard protocol for management of such teeth.

\section{REFERENCES}

1. Cotti E, Mereu M, Lusso D Regenerative treatment of an immature, traumatized tooth with apical periodontitis: report of a case. J Endod 2008 ; 34: 611-6.

2. Rafter MApexification: a review. Dent Traumat 2005; 21: 1-8.

3. El-Meligy OA, Avery DR Comparison of apexification with mineral trioxide aggregate and calcium hydroxide. Pediat Dent 2006;28: 248-53.

4. Peter E Murray, Franklin Garcia-Godoy and Kenneth M. Hargreaves: Regenerative Endodontics:A Review of Current status and a Call for action. J Endod 2007;33:377-390

5. Sahng G.Kin, Charles Solomon,Takahiro Sujuki,Nan Jiang,Jian Zheng,Mo chen,Songhee Song,Jeremy J. Mao: Effect of growth factors on dental cells/progenitor cells; DCNA2012; 56(3): 563-575

6. T. Bezgin1, A. D. Yılmaz2, B. N. C_elik1 \& H. Sonmez. Concentrated platelet-rich plasma used in root canal revascularization: 2 case reports Int Endod J 2014; 47: 41-49.

7. Garcia-Godoy F, Murray PE Recommendations for using regenerative endodontic procedures in permanent immature traumatized teeth. Dental Traumat 2012; 28:33-41.

8. Iwaya SI, Ikawa M, Kubota M. Revascularization of an Immature Permanent Tooth with Apical Periodontitis and Sinus Tract. Dent Traumatol. 2001; 17 (4):185-7.

9. Banchs F, Trope M Revascularization of immature permanent teeth with apical periodontitis: new treatment protocol? J Endod 2004; 30: 196-200.

10. Ding RY, Cheung GS, Chen J, Yin XZ, Wang QQ, Zhang CF Pulp revascularization of immature teeth with apical periodontitis: a clinical study. J Endod 2009; 35: 745-9.

11. Ganesh Jadhav, Naseem Shah, and Ajay Logani. Revascularization with and without Platelet-rich Plasma in Nonvital, Immature, Anterior Teeth: A Pilot Clinical Study. J Endod 2012;38:1581-1587.

12. Petrino JA, Boda KK, Shambarger S, Bowles WR, McClanahan SB Challenges in regenerative endodontics: a case series. J Endod 2010; 36: 536-41

13. Cehreli ZC, Isbitiren B, Sara S, Erbas G. Regenerative endodontic treatment (revascularization) of immature necrotic molars medicated with calcium hydroxide: a case series. J Endod 2011;37: 1327-30.

14. Hargreaves K, Law A. Regenerative endodontics. In: Hargreaves K, Cohen S, eds. Pathways of the Pulp, 10th ed. St Louis: Mosby Elsevier; 2011:602-19.

15. Shah N, Logani A, Bhaskar U, et al. Efficacy of revascularization to induce apexification/ apexogenesis in infected, nonvital, immature teeth: a pilot clinical study. J Endod 2008; 34:919-2.

16. Nosrat A, Homatounfar N, Oloomi K. Drawbacks and unfavorable outcomes of regenerative endodontic treatments of necrotic immature teeth: a literature review and report of a case. J Endod 2012; 38:1428-34.

17. Lenzi R, Trope M. Revitalization procedures in two traumatized incisors with different biological outcomes. J Endod 2012; 38:411-4.

18. Thibodeau B, Teixeira F, Yamauchi N. Pulp revascularization of immature dog teeth with apical periodontitis. J Endod 2007; $33: 700-5$.

19. Mohamed M. Nagy, Hosam E. Tawfik, Ahmed Abdel Rahman Hashem, Ashraf M. Abu-Seida. Regenerative Potential of Immature Permanent Teeth with Necrotic Pulps after Different Regenerative Protocols. J Endod 2014;40:192-198.

20. Ashraf f. Fouad \& Ali nosrat Pulp regeneration in previously infected root canal space. Endo Topics 2013, 28, 24-37

21. K.Reynolds, J.D. Johnson \& N.Cohenca: Pulp revascularization of necrotic bilateral bicuspids using a modified novel technique to eliminate potential coronal discolouration: a case report: Int Endod J 2009; 42(1): 84-92.

22. Sonia Regina Panzarini, Carolina Lunardelli Trevisan, Daniela Atili Brandini, Wilson Roberto Poi, Celso Koogi Sonoda, Eloa Rodrigues Luvizuto, Claudia Leticia Vendrame dos Santos..Intracanal dressing and root canal filling materials in tooth replantation: a literature review Dent Traumatol 2012; 28: $42-48$

23. Chen H, Teixeira FB, Ritter AL, Levin L, Trope M. The effect of intracanal anti-inflammatory medicaments on external root resorption of replanted dog teeth after extended extra-oral dry time. Dent Traumatol 2008;24:74-8.

24. Bryson EC, Levin L, Banchs F, Abbott PV, Trope M. Effect of immediate intracanal placement of Ledermix Paste on healing of replanted dog teeth after extended dry times. Dent Traumatol 2002;18:316-21. 
25. Wong KS, Sae-Lim V. The effect of intracanal Ledermix on root resorption of delayed-replanted monkey teeth. Dent Traumatol 2002;18:309-15.

26. I-Young Jung, Seung-Jong Lee, Kenneth M. Hargreaves. Biologically Based Treatment of Immature Permanent Teeth with Pulpal Necrosis: A Case Series. J Endo.2008;34 (7), 876877.

27. Torabinejad M, Parirokh M. Mineral trioxide aggregate: a comprehensive literature review: part II-leakage and biocompatibility investigations. J Endod 2010;36: 190-202.

28. Torabinejad M, Turman M Revitalization of tooth with necrotic pulp and open apex by using platelet-rich plasma: a case report. J Endod 2011;37: 265-8.

29. Harold E. Goodis, Bassam Michael Kinaia, Atheel M. Kinaia, Sami M.A. Chogle Regenerative Endodontics andTissue Engineering What the Future Holds? DCNA 2012; 56(3): 67789.
30. Baum BJ; Biomedical research, oral medicine, and the future; Oral surgery, Oral medicine, Oral pathology, Oral radiology, J Endod 2002; 94:141-8.

31. Murray PE, Garcia-Godoy F, Hargreaves KM. Regenerative endodontics: a review of current status and a call for action. J Endod 2007; 33:377-90.

32. Iwaya S, Ikawa M, Kubota M. Revascularization of an immature permanent tooth with periradicular abscess after luxation. Dent Traumatol 2011;27:55-8.

33. Mohamed M. Nagy, Hosam E. Tawfik, Ahmed Abdel Rahman Hashem, and Ashraf M. Abu-Seida, Regenerative Potential of Immature Permanent Teeth with Necrotic Pulps after Different Regenerative Protocols .J Endod 2014; 40:192-198.

34. Shimizu E, Jong G, Partridge N, Rosenberg PA, Lin LM. Histologic observation of a human immature permanent tooth with irreversible pulpitis after revascularization/regeneration procedure. J Endod 2012: 38: 1293-1297.

Source of Support: Nil, Conflict of Interest: None Declared 